\title{
High insulin exacerbates neutrophil-endothelial cell adhesion through endothelial surface expression of intercellular adhesion molecule-1 via activation of protein kinase $C$ and mitogen-activated protein kinase
}

\author{
M. Okouchi, N. Okayama, M.Shimizu, H. Omi, T. Fukutomi, M. Itoh \\ First Department of Internal Medicine, Nagoya City University Medical School, Nagoya Japan
}

\begin{abstract}
Aims/hypothesis. The association of insulin resistance and compensatory hyperinsulinaemia with increased coronary events in diabetic patients is poorly understood. There are few publications about the direct atherogenic actions of insulin on the endothelium compared with those on vascular smooth muscle cells. The aim of this study was to elucidate whether high insulin directly affects neutrophil-endothelial cell adhesion and surface expression of endothelial adhesion molecules. We also examined what intracellular mechanisms are involved in these events.

Methods. Studies of adhesion between neutrophils from healthy volunteers and human umbilical vein endothelial cells incubated in insulin-rich medium were carried out. Adhered neutrophils were quantified by measuring their myeloperoxidase activities
\end{abstract}

and surface expression of endothelial adhesion molecules was examined using an enzyme immunoassay. Results. High insulin enhanced neutrophil-endothelial cell adhesion with an increase in the expression of intercellular adhesion molecule-1 but not E-selectin or P-selectin. Both phenomena were attenuated by pretreatment with protein kinase $\mathrm{C}$ inhibitors and a mitogen activated protein kinase inhibitor.

Conclusions/interpretation. These results suggest that hyperinsulinaemia causes vascular injury by directly exacerbating neutrophil-endothelial cell adhesion through increasing endothelial expression of intercellular adhesion molecule-1 via activation of protein kinase and mitogen activated protein kinase pathways. [Diabetologia (2002) 45:556-559]

Keywords Insulin resistance, hyperinsulinaemia, diabetes, atherosclerosis, vascular injury.
The risk of cardiovascular diseases in diabetic patients and even in those with IGT are associated with insulin resistance, two- to threefold higher than that in control subjects [1]. The United Kingdom Prospective Diabetes Study (UKPDS) and other similar stud-

Received: 5 September 2001 and in revised form: 26 November 2001

Corresponding author: M. Okouchi, First Department of Internal Medicine, Nagoya City University Medical School, $1 \mathrm{Ka}-$ wasumi, Mizuho-cho, Mizuho-ku, Nagoya 467-8601, Japan, e-mail: okochi@med.nagoya-cu.ac.jp

Abbreviations: AMI, Acute myocardial infarction; ICAM-1, intercellular adhesion molecule-1; HUVEC, human umbilical vein endothelial cells; PMN, polymorphonuclear neutrophils (leukocytes); PKC, protein kinase C; MAP, mitogen activated protein ies indicated that intensive control of blood glucose in diabetic patients prevents and slows the progression of microvascular complications, but has little effect on the prevention of macrovascular complications i.e. acute myocardial infarction (AMI) [2]. Excessive macrovascular diseases in diabetes have thus been considered to be due to insulin resistance and/or hyperinsulinaemia.

A recent study has shown that vascular inflammation with atherosclerosis is responsible for the onset of AMI [3]. Adhesion of leukocytes to the endothelium, which is regulated by several endothelial adhesion molecules such as intercellular adhesion molecule-1 (ICAM-1), E-selectin and P-selectin, is the first and crucial step in both atherosclerosis and vascular inflammation. Whereas endothelial dysfunction induced by insulin resistance and/or hyperinsulin- 
aemia is an early and prominent event in atherosclerosis, so far there have been few reports about the direct atherogenic action of high insulin on the endothelium compared to vascular smooth muscle cells. We evaluated the direct atherogenic actions of high insulin on the endothelium, particularly the enhancement of neutrophil-endothelial cell adhesion and the involvement of endothelial adhesion molecule expression. We also examined the intracellular mechanisms involved in these events.

\section{Materials and methods}

This study was carried out in accordance with the Declaration of Helsinki as revised in 1996.

Cell culture. Human umbilical vein endothelial cells (HUVEC; Kurabo, Osaka, Japan) were cultured in collagen I-coated plates in CS-C medium (45\% DMEM, 45 \% Ham's F12 medium, $10 \%$ foetal bovine serum, $10 \mathrm{ng} / \mathrm{ml}$ acidic-fibroblast growth factor, $50 \mathrm{U} / \mathrm{ml}$ heparin, and $15 \mathrm{mmol} / \mathrm{l} \mathrm{HEPES}$; Cell Systems, Kirkland, Washington., USA) with antibiotic-antimicotic (Gibco BRL, Grand Island, N.Y., USA) at $37^{\circ} \mathrm{C}$ in a $100 \%$ humidified atmosphere containing $5 \% \mathrm{CO}_{2}$.

Neutrophil isolation. Human neutrophilic polymorphonuclear leukocytes (PMN) were isolated from venous blood of healthy volunteers, who gave their informed consent, using standard dextran sedimentation and gradient separation on histopaque 1077 (Sigma, St. Louis, Mo., USA). This procedure yields a PMN population which is $98 \%$ pure (acetic acid-crystal violet staining) and 95 to $98 \%$ viable (trypan blue exclusion). No platelet contamination was seen in the isolated PMN examined using a microscope.

Neutrophil-endothelial cell adhesion assay. A neutrophil-endothelial cell adhesion assay was carried out [4]. Briefly, HUVEC were cultured on 48-well plates, and incubated for $48 \mathrm{~h}$ with or without human regular insulin (Novolin R, Novo-Nordisk, Bagsvaard, Denmark). After treatment, medium was replaced with Hank's balanced salt solution (HBSS), and neutrophils $\left(1 \times 10^{5}\right.$ cells/well $)$ were added and allowed to adhere for $30 \mathrm{~min}$. After washing out non-adhered neutrophils, adhered neutrophils were quantified using a myeloperoxidase (MPO) assay. Neutrophil adhesion was expressed as the ratio of MPO activity of adhered neutrophils to that of the total neutrophils $\left(1 \times 10^{5}\right.$ cells $)$.

Surface expression assay of endothelial adhesion molecules. The surface expression of endothelial adhesion molecules (ICAM-1, P-selectin, E-selectin) was measured [4]. Briefly, after treatment of cells with or without insulin for $48 \mathrm{~h}$ in 24 well plates, cells were incubated with an anti-adhesion molecule antibody (primary antibody; diluted 1:100-250; Sigma) for $60 \mathrm{~min}$, followed by incubation with horseradish peroxidase-conjugated goat anti-mouse IgG (diluted 1:2500-5000; Sigma) for $60 \mathrm{~min}$ in HBSS and phosphate-buffered saline containing $5 \%$ foetal calf serum. Cells were then incubated for $60 \mathrm{~min}$ in the dark with $0.25 \mathrm{ml}$ of $0.003 \% \mathrm{H}_{2} \mathrm{O}_{2}$ plus $0.1 \mathrm{mg} /$ $\mathrm{ml} \mathrm{3,3',5,5'-tetramethylbenzidine} \mathrm{as} \mathrm{a} \mathrm{substrate.} \mathrm{The} \mathrm{reaction}$ was stopped by adding $75 \mu \mathrm{l}$ of $8 \mathrm{NH}_{2} \mathrm{SO}_{4}$, and the samples were transferred to 96 -well plates which were read at $450 \mathrm{~nm}$ on a plate reader.
Treatment protocols. Human umbilical vein endothelial cells were preincubated for $3 \mathrm{~h}$ before an assay of neutrophil-endothelial cell adhesion or surface expression with or without the following intracellular second messenger inhibitors; a classic protein kinase C (PKC) inhibitor, Gö6976 (Calbiochem, San Diego, Calif., USA), a broad PKC inhibitor, Gö6983 (Calbiochem), a mitogen-activated protein (MAP) kinase inhibitor, PD98059 (Calbiochem), and a phosphatidylinositol-3 (PI-3) kinase inhibitor, wortomannin (Calbiochem).

Statistical analysis. All experiments were carried out three times in triplicate with four different endothelial cell preparations. All values are expressed as means \pm SEM. Data were analysed using a one-way ANOVA with Fisher's Exact test for multiple comparisons. Statistical significance was considered as a $p$ value of less than 0.05 .

\section{Results}

Effects of high insulin on PMN adhesion to HUVEC and surface expression of endothelial adhesion molecules. Insulin at a concentration of $100 \mu \mathrm{U} / \mathrm{ml}(0.609$ $\mathrm{nmol} / \mathrm{l}$ ) increased both PMN adhesion and endothelial ICAM-1 expression within 48 h (Fig. 1, 2). However, endothelial expression of P-selectin and E-selectin was not affected by high insulin. Addition of an antibody specific for ICAM-1 $(10 \mu \mathrm{g} / \mathrm{ml})$ attenuated the enhanced-PMN adhesion to HUVEC mediated by the high insulin stimulation while neither an anti-P-selectin nor an anti-E-selectin antibody $(10 \mu \mathrm{g} / \mathrm{ml})$ affected the event (control: $6.9 \pm 0.3 \%$; high insulin: $11.5 \pm 0.1 \%, p<0.001$ vs control; high insulin + anti-ICAM-1 antibody $8.3 \pm 0.3 \%, \quad p<$ 0.001 vs high insulin; high insulin + anti-P-selectin antibody $11.8 \pm 0.4 \%$; high insulin + anti-E-selectin antibody $11.2 \pm 0.3 \%)$.

\section{Effects of intracellular second messenger inhibitors on} the high insulin-mediated PMN adhesion and ICAM1 expression. We attempted to define the signal transduction pathways involved in the high insulin-mediated endothelial events. The enhanced neutrophil-endothelial cell adhesion caused by $100 \mu \mathrm{U} / \mathrm{ml}$ insulin for $48 \mathrm{~h}$ was attenuated by a classic PKC inhibitor, Gö6976 (10 nmol/l) and a broad PKC inhibitor, Gö6983 (0.1 $\mu \mathrm{mol} / \mathrm{l})$ (Fig. 1A).

In addition, we examined the participation of two insulin receptor-mediated tyrosine kinases, MAP kinase and PI-3 kinase, in the high insulin-mediated event and found that a MAP kinase inhibitor, PD98059 $(10 \mu \mathrm{mol} / \mathrm{l})$ but not a PI-3 kinase inhibitor, wortmannin $(10 \mathrm{nmol} / \mathrm{l})$ attenuated the phenomenon (Fig. 1B).

Furthermore, we found that the enhanced expression of endothelial ICAM-1 caused by $100 \mu \mathrm{U} / \mathrm{ml}$ insulin for $48 \mathrm{~h}$ was also inhibited by the same concentration of Gö6976 (Fig.2A), Gö6983 (Fig.2B) and PD98059 (Fig.2C). 


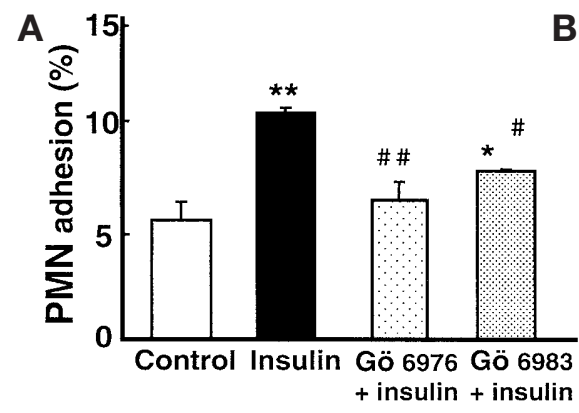

Fig.1 (A, B). Effects of intracellular second messenger inhibitors on the enhanced PMN adhesion to HUVEC mediated by high insulin. Cells were treated without (control) or with $100 \mu \mathrm{U} / \mathrm{ml}$ insulin for $48 \mathrm{~h}$ (insulin) in the presence or absence of a classic PKC inhibitor, $10 \mathrm{nmol} / 1$ Gö6976 (A), a broad PKC inhibitor, 0.1 umol/1 Gö6983 (A), a MAP kinase inhibitor, $10 \mu \mathrm{mol} / 1$ PD98059 (B), and a PI-3 kinase inhibitor, $10 \mathrm{nmol} / \mathrm{l}$ wortomannin (B). Values are expressed as means \pm SEM. ${ }^{*} p<0.01, * * p<0.001$ compared to the respective control, $\# p<0.01, \# \# p<0.001$ compared to the cells treated with high insulin alone

\section{Discussion}

We found evidence for the direct atherogenic actions of insulin which enhanced neutrophil-endothelial cell adhesion at a concentration of $100 \mu \mathrm{U} / \mathrm{ml}$ incubated for $48 \mathrm{~h}$. The insulin concentration which we used, $100 \mu \mathrm{U} / \mathrm{ml}$ is thought to be around the physiological concentration present in the insulin-resistant condition because blood concentrations greater than $100 \mu \mathrm{U} / \mathrm{ml}$ can be found in insulin resistant subjects [5]. In addition, similar insulin concentrations around $100 \mu \mathrm{U} / \mathrm{ml}$ were used in other experiments [6].

Fig. 2 (A-C). Effects of PKC and MAP kinase inhibitors on the enhanced surface expression of endothelial ICAM-1 mediated by high insulin. Cells were treated without (control) or with $100 \mu \mathrm{U} / \mathrm{ml}$ insulin for $48 \mathrm{~h}$ (insulin) in the presence or absence of a classic PKC inhibitor, $10 \mathrm{nmol} / 1$ Gö6976 (A), a broad PKC inhibitor, $0.1 \mu \mathrm{mol} / \mathrm{l}$ Gö6983 (B), and a MAP kinase inhibitor, $10 \mu \mathrm{mol} / 1$ PD98059 (C). Values are expressed as means \pm SEM. ${ }^{*} p<0.001$ compared to the respective control, $\# p<0.001$ compared to the cells treated with high insulin alone

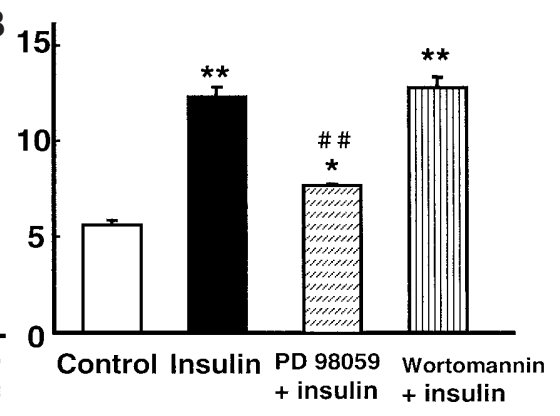

Because it has been reported that neutrophil-endothelial cell adhesion is modulated by several endothelial adhesion molecules, we hypothesized that the enhanced adhesion caused by high insulin was secondary to the induction of adhesion molecules on insulin-activated endothelial cells. We found that the enhanced PMN adhesion observed with $100 \mu \mathrm{U} / \mathrm{ml}$ insulin incubated for $48 \mathrm{~h}$ was associated with an increase in the expression of endothelial ICAM-1 but not E-selectin or P-selectin. This finding was strongly confirmed by the inhibitory effect of an anti-ICAM-1 antibody on the high insulin-enhanced PMN adhesion. Our results agree with a study [7] which showed that the surface expression of E-selectin rapidly increased after activation of HUVEC with tumour necrosis factor-alpha or interleukin-1 and then decreased to below detection values within $24 \mathrm{~h}$, whereas ICAM-1 expression gradually increased, reached a plateau after $24 \mathrm{~h}$, and remained constant for 3 days.

Next we investigated the intracellular signal transduction pathways which could be involved in the high insulin-mediated neutrophil-endothelial cell adhesion and endothelial ICAM-1 expression. We found that two distinct PKC inhibitors, Gö6976 and Gö6983 attenuated both, suggesting the involvement of this pathway. Little has been known about the correlation between the insulin actions and a PKC pathway, however the involvement of a PKC pathway in insulin-like growth factor- 1 actions has been reported [8].

Another report has indicated that insulin has two different actions considered to be either atherogenic through a MAP kinase pathway or anti-atherogenic through a PI-3 kinase pathway [9]. We therefore further evaluated the correlation between the insulin actions and these insulin receptor-mediated tyrosine kinases and found that both endothelial events medi-

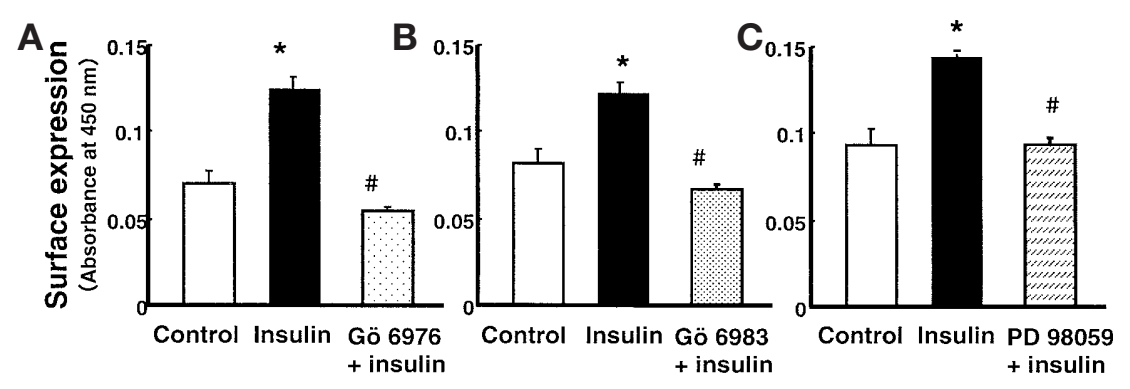


ated by high insulin were attenuated by pretreatment with a MAP kinase inhibitor, PD98059 but not a PI 3kinase inhibitor, wortmannin. These results are consistent with a previous report [10], showing that MAP kinase activation is integral to the increase in endothelial ICAM-1.

In conclusion, our study casts a new light on the direct atherogenic actions of insulin on the endothelium which results from enhanced neutrophil-endothelial cell adhesion through an increase in the surface expression of endothelial ICAM-1. These phenomena were likely to be mediated by the activation of PKC and MAP kinase pathways. The evidence on the intracellular signal transduction pathways involved in the events mediated by high insulin should facilitate the development of better pharmacologic agents to prevent vascular complications in patients with diabetes and IGT, particularly those with insulin resistance.

\section{References}

1. DeFronzo RA (1997) Insulin resistance: a multifaceted syndrome responsible for NIDDM, obesity, hypertension, dyslipidaemia and atherosclerosis. Neth J Med 50: 191-197

2. UK Prospective Diabetes Study (UKPDS) Group (1998) Intensive blood-glucose control with sulphonylureas or insulin compared with conventional treatment and risk of complications in patients with type 2 diabetes (UKPDS 33). Lancet 352: 837-853
3. Ikeda U, Ikeda M, Kano S, Shimada K (1994) Neutrophil adherence to rat cardiac myocyte by proinflammatory cytokines. J Cardiovasc Pharmacol 23: 647-652

4. Okayama N, Ichikawa H, Coe L, Itoh M, Alexander JS (1998) Exogenous NO enhances hydrogen peroxide-mediated neutrophil adherence to cultured endothelial cells. Am J Physiol 274: 820-826

5. Aljada A, Saadeh R, Assian E, Ghanim H, Dandona P (2000) Insulin inhibits the expression of intercellular adhesion molecule- 1 by human aortic endothelial cells through stimulation of nitric oxide. J Clin Endocrinol Metab 85: 2572-2575

6. Kahn AM, Husid A, Odebunmi T, Allen JC, Seidel CL, Song T (1998) Insulin inhibits vascular smooth muscle contraction at a site distal to intracellular $\mathrm{Ca} 2+$ concentration Am J Physiol 274: 885-892

7. Leeuwenberg JF, Smeets EF, Neefjes Jj et al. (1992) E-selectin and intercellular adhesion molecule-1 are released by activated human endothelial cells in vitro. Immunology 77: 543-549

8. Yano K, Bauchat JR, Liimatta MB, Clemmons DR, Duan C (1999) Down-regulation of protein kinase C inhibits insulin-like growth factor I-induced vascular smooth muscle cell proliferation, migration, and gene expression. Endocrinology 140: 4622-4632

9. Hsueh WA, Law RE (1999) Insulin signaling in the arterial wall. Am J Cardiol 84: 21J-24J

10. Tamura DY, Moore EE, Johnson JL, Zallen G, Aiboshi J, Silliman CC (1998) p38 mitogen-activated protein kinase inhibition attenuates intercellular adhesion molecule-1 upregulation on human pulmonary microvascular endothelial cells. Surgery 124: 403-408 